Everaldo Cescon

Doutor em Teologia

Professor na Universidade de Caxias do Sul e

da Pontifícia Universidade Católica do Rio Grande do Sul

Brasil

\title{
O problema de Deus e do seu acesso e a experiência de Deus
}

\section{INTRODUÇÃO}

O tema de Deus foi desenvolvido pela primeira vez por Zubiri em 1935, com o famoso artigo "En torno al problema de Dios" (1). Treze anos mais tarde professaria dois cursos que teriam esta mesma reflexão como pauta. Tal preocupação teológica culminaria no curso ministrado em 1971-1972 intitulado El problema teologal del hombre: Dios, religión, cristianismo. Esta temática nunca mais desapareceu do seu horizonte filosófico. É parte constitutiva de sua filosofia.

Deus e o homem se implicam de tal forma no pensamento de X. Zubiri que um sempre tem a mão estendida na direção do outro. Por isso, afirma com segurança que o problema de Deus é o problema do homem, que o problema de Deus se põe aos homens "por el mero hecho de ser hombres", é a "realidad humana misma en su constitutivo problematismo" (2). "No es la adición de dos 'objetos', hombre 'y' Dios, sino que es el análisis de la realidad humana en cuanto constitutivamente envuelve la versión a la realidad divina" (3).

\section{O PROBLEMA DE DEUS}

\section{O aparecimento do problema de Deus}

O problematismo da pessoa humana se mostra como inquietude, voz e vontade que clamam por um absoluto. Fazer-se "pessoa é busca do fundamento" de meu

(1) Naturaleza, Historia, Dios, Madrid (1944) 199911. Daqui por diante, simplesmente NHD.

(2) El hombre y Dios, Madrid: Alianza Editorial/SEP (1984), 19986, p. 12. Daqui para diante, simplesmente HD. El problema filosófico de la historia de las religiones, (Edição de Antonio González), Madrid: Alianza Editorial/Fundación Xavier Zubiri, 1993, p. 191. Daqui para diante, simplesmente PFHR.

(3) HD 13

(4) "Ser fundamento es más que ser objeto. El objeto es mero objectum, algo que está 'frente' a mí 
relativo ser absoluto, busca de uma "realidade-fundamento" e não de uma "realidadeobjeto" (4), estranha às próprias coisas reais. Este problematismo da realidade-fundamento não é algo que leva ao problema de Deus; ele é o problema de Deus, e pertence à dimensão de minha pessoa religada, "ligada" ao poder do real. O problema de Deus é relativamente o drama humano, e o que se busca não é uma abstração, ou o resultado de uma elaboração lógica, nem é um ente supremo, mas a realidade suprema (5):

"La realidad-fundamento es la solución del enigma de la realidad y de mi realidad personal. Este problematismo de la realidad-fundamento no es algo que lleva al problema de Dios sino que es formalmente el "problema de Dios". Lo que la "religación" manifiesta experiencial pero enigmáticamente es Dios como problema. El problema de Dios pertenece, pues, formal y constitutivamente a la constitución de mi propia persona en tanto tiene que hacerse inexorablemente su propia realidad, su propia "figura de ser" absoluto "con" las cosas estando "en" la realidad" (6).

"El hombre no "tiene" el problema de Dios, sino que la constitución de su Yo "es" formalmente el problema de Dios" (7).

“Justificar la realidad de Dios no es montar razonamientos especulativos sobre razonamientos especulativos, sino que es la explanación intelectiva de la marcha efectiva de la religación"..." (8). Não se trata de saber se existe uma realidade divina, mas se dentro da realidade, que sem dúvida existe, alguma das suas dimensões pode ser entendida como Deus (9).

\section{A marcha efetiva da religación à realidade divina}

Três indagações sobre Deus centralizam a atenção dos homens: "existe?", “como se chega a Ele?", “qual é sua natureza?". Zubiri ocupou-se somente do ponto de partida para chegar a Ele. Depois de analisar as vias clássicas, reuniu-as em dois grupos: as cosmológicas, das quais toma Aristóteles e São Tomás como representantes, e as antropológicas, representadas por Santo Agostinho, Kant e Schleiermacher. Primeiro, procuramos demonstrar como, para Zubiri, o caminho das vias clássicas não é "adequado" (10). Em seguida, ocupamo-nos da novidade trazida pelo ponto de

según él es en y por sí mismo, y en ello se agota su modo de presencia. En cambio, un fundamento es una realidad que ciertamente se me muestra, pero no 'frente' a mí sino 'en' mi inteligencia, no solo en cuanto en y por sí mismo es lo que es, sino en cuanto está fundamentando mi vida entera" (HD 158-159; cf. também C. DÍAZ, "El hombre y Dios en Xavier Zubiri": Revista Agustiniana 34 (1993) 165-193, p. 169s).

(5) HD 130, 427.

(6) HD 110.

(7) HD 116, PFHR 191, 258.

(8) HD 134

(9) HD 230.

(10) Para Pintor-Ramos, tal posição é "un camino precipitado y refleja un modo de pensar inconsistente dentro de la filosofía de Zubiri" porque "supondría un salto desde la realidad dada a un ser perteneciente a otro orden heterogéneo, salto que solo sería posible interponiendo entre él y la realidad la mediación de conceptos teóricos de uno u otro tipo" (A. PINTOR-RAMOS, 
partida da "vía de la religación”. E por último, centralizamo-nos no aparecer do problema de Deus.

\section{a) A insuficiência das vias cosmológicas de acesso a Deus}

Filósofos e teólogos clássicos, quando se perguntaram pelo acesso a Deus, pensaram que certos "fatos" e "coisas" possibilitavam um processo demonstrativo que concluía em Deus. Tomaram como ponto de partida a realidade considerada como "eso que llamamos naturaleza", isto é, a "estructura del cosmos" (11). Este processo culminou nas "célebres cinco vias de São Tomás" (12). Contudo, Zubiri se pergunta se tais "hechos" (13) são realmente o que as palavras dizem. Conclui que, sob a aparência de "hechos", o que realmente se põe são "interpretacciones" de fatos e, por isso, toda a argumentação sustentase na filosofia subjacente, neste caso da filosofia aristotélica. Tomemos um exemplo: o "movimiento" na primeira via aristotélico-tomista. Diz Zubiri:

"Para santo Tomás, el movimiento es, como para Aristóteles, un estado del ente móvil que consiste en el paso de potencia a acto. Este es el "hecho" sobre el que se apoya la "prima via". Ahora bien, esto no es ni puede ser un hecho: es una interpretación de la realidad del movimiento. Y todo lo que el nudo hecho del movimiento tiene de inconcuso, tiene de problemática aquella interpretación aristotélica" (14).

Deve-se distinguir três elementos nesta afirmação de Zubiri: há um "hecho nu" do movimento, e este tem caráter indiscutível; há também uma "interpretación aristotélica" do fato que já é discutível; e há, finalmente, o "sentido" em que São Tomás utiliza o movimento como ponto de partida: não é o fato nu, mas a interpretação do mesmo, segundo a filosofia aristotélica.

Zubiri deixa bem claro o que pretende:

“... no pretendo que esos cinco razonamientos no sean concluyentes, sino que contra lo que expresamente se afirma en ellos, no parten de hechos sino de algo muy distinto, a saber, de una interpretación metafísica de la realidad sensible. [...] la base de discusión de santo Tomás no son los hechos sino la

“Religación y “prueba” de Dios en Zubiri”: Razón y Fe, Tomo 218, n. 1081 (nov. 1988) 319-336, p. 326-327).

(11) HD 118 .

(12) "El movimiento o cambio en las cosas, el orden de causas eficientes, la generación y corrupción de los seres, los grados de perfección en los seres, la homogeneidad en el modo de obrar de los seres" (HD 119).

(13) HD 119-120.

(14) HD 119. A primeira via se basearia na teoria do ato e potência; a segunda numa concepção crítica da causalidade eficiente que, segundo Zubiri, não é admissível depois da crítica de Hume; a terceira esqueceria que há seres necessariamente contingentes; a quarta suporia a existência de graus de perfeição nos seres cósmicos, o que não consta; a quinta veria ordenação onde só cabe ver convergência.

(15) HD 121. 
metafísica de Aristóteles, que es para santo Tomás la razón misma en cuanto tal. A fuerza de considerarla como la metafísica del sentido común se acaba por identificarla con los hechos..." (15).

Mesmo que tais vias fossem válidas (16), "el término a que conducen no es Dios en cuanto Dios" (17) e sim um motor imóvel, uma causa primeira eficiente, um ente necessário, um ser em plenitude de perfeição e uma inteligência suprema. Aquilo a que se chega através de concatenação lógica de conceitos é uma realidadeobjeto, e não a realidade-fundamento. E mais, essas "ultimidades" se identificam entre si? Supondo que se prove tal identificação, “isignifica esto que se ha probado sin más que ese ente supremo sea "formalmente" Dios, lo que entendemos por Dios?" (18).

Duns Escoto, com a intenção de reforçar tal raciocínio, dividiu-o em dois tempos: primeiro, provar a existência de um ser que seja "primeiro" e, em seguida, que essa realidade primeira é "infinita" e, por ser infinita, Deus. Zubiri replica: e se Deus fosse infinito por ser Deus e não o contrário? Em qualquer caso, seguimos sem oferecer um término à via que seja formalmente o que entendemos por Deus quando a ele nos dirigimos (19). "En el punto de llegada de estas argumentaciones nos encontramos con un ente supremo", uma "esencia metafísica"; porém, o que buscamos é algo mais concreto: "una realidad última, fuente de todas las posibilidades que el hombre tiene, y de quien recibe, suplicándole, ayuda y fuerza para ser" (20). Este ser último não reúne as qualidades de personalidade do Deus a quem o homem busca e invoca nas religiões. Como deve ser esse Deus formalmente Deus? Não um Deus-objeto, mas um Deus-fundamento.

\section{b) A insuficiência das vias antropológicas de acesso a Deus}

São Tomás não formulou as vias antropológicas com a mesma exatidão das vias cosmológicas; no entanto, outros clássicos as priorizaram, e passaram a ser, em geral, as preferidas depois da crítica kantiana. Ao mencioná-las, Zubiri cita três autores: a via das "verdades" que, partindo da inteligência humana na qual se dão, clamam com força pela existência de uma Verdade Subsistente (Santo Agostinho); a via do "imperativo del deber" que, procurando na vontade humana, postula a existência de um Sumo e Ótimo Bem (Kant); e a via do "sentimiento incondicional de dependencia", que nos faz entrever a realidade do Infinito Incondicionado (Schleiermacher) (21).

(16) Zubiri admite que, se partisse do homem e de suas ações, o ponto de partida das vias seria válido (excetuando a quinta via) porque se trataria de fatos. Para Alluntis Learreta, esta afirmação de Zubiri invalida, em grande parte, sua própria crítica. Se alguém lê a ampla exposição que $\mathrm{S}$. Tomás faz da primeira via baseada no movimento na Summa contra gentiles verá que fala também de movimentos ou ações humanas. Portanto, são vias não somente cosmológicas, mas também antropológicas.

(17) HD 121

(18) HD 122.

(19) Ibidem.

(20) HD 123

(21) HD 123-124.

(22) HD 124. 
O que o pensador basco pretende discutir é o ponto de partida: “ ¿son realmente "hechos" o "datos"?" (22). São apenas aspectos, momentos, fragmentos do homem -inteligência, vontade, sentimento- mas nenhum dos três tem presente a "realidade humana" como totalidade, que é a autenticamente necessitada de um fundamento. Ademais, cada um desses momentos, enquanto constituído como ponto de partida, "es todo menos una constatación irrecusable" (23). Santo Agostinho, por exemplo, "parte de "la" verdad como de algo que mora en el interior del hombre, pero en oposición a "las" verdades". Nesse sentido, "el "hecho" del que en realidad parte ...no es precisamente la inteligencia, sino el dualismo radical que hay en ella entre "la" verdad y "las" verdades" (24).

Como nas vias cosmológicas, há uma deficiência parecida: tomam-se "interpretaciones" em vez de "hechos", teorias sobre as coisas em vez das coisas mesmas, como ponto de partida (25). E "el punto de llegada no es Dios en cuanto Dios, pero su realidad no envuelve formalmente una referencia al resto del mundo real sino tan solo al hombre" (26). Ocorre uma "segregación del hombre frente al mundo real, conduce a un Dios también más o menos segregado de éste" (27). Em suma, levando a um Deus ausente da realidade e ao qual se deve, num processo ulterior, inserir como fundamento. É o que faz de Deus um objeto.

Resumindo, tanto as vias cosmológicas como as antropológicas deveriam partir de "fatos indiscutíveis", porém partem de "interpretações de fatos"; e acedem a uma realidade de Deus que não é "Deus-fundamento", mas quase um "deus-objeto", segregado do mundo (28).

\section{c) A "vía de la religación"}

Visto que o caminho proposto a partir de fatos cosmológicos e antropológicos resulta inadequado, Zubiri propõe um percurso para chegar a Deus enquanto tal, a partir do homem como totalidade. Utiliza-se de sua peculiar doutrina sobre a inteligência "sentiente" que apreende as coisas em impressão de realidade, da procedência de "realidad" a "ser", de sua interpretação da causalidade com funcionalidade e do "poder" como domínio não causal, da novidade da religación da pessoa ao poder do real, etc, e esboça uma nova via (29): a "vía de la religación" (30). São passos (31) que enunciam uma novidade não só terminológica, mas também de sentido:

(23) HD 125 .

(24) Ibidem.

(25) Ibidem.

(26) HD 127.

(27) HD 126-127.

(28) Cf. C. ANIZ IRIARTE, "Punto de partida en el acceso a Dios. Vía de la religación, de Zubiri": Estudios Filosóficos 35 (1986) 237-268, p. 246.

(29) "Via", para Zubiri, é conhecimento, inteligir inquisidor, é busca do fundamento, é "marcha" da razão (IR 25-133).

(30) HD 132.

(31) A nível noético, González Álvarez esquematiza a via da religación em oito passos: 1) conhecimento do ser das coisas do mundo até demonstrar sua contingência radical e a contingência do mundo em geral; 2) conhecimento do homem; 3) nascimento da idéia de dependência do mundo e do homem e necessidade de que se relacionem com um ser suficiente; 4) 
a) "El hombre es una realidad personal cuya vida consiste en hacer, física y realmente, su Yo. La persona humana se realiza como persona apoyada en el poder de lo real. Solo en y por este apoyo puede la persona vivir y ser: es el fenómeno de la 'religación"”, (32).

b) "La persona no está simplemente vinculada a las cosas o dependiente de ellas, sino que está constitutiva y formalmente religada al poder de lo real, el cual constituye eo ipso la fundamentalidad misma de la vida personal" (33).

c) "La "religación" no es mera "vinculación" ni es un "sentimiento de dependencia" sino la versión constitutiva y formal al poder de lo real como fundamento de mi vida personal" (34). A pergunta pela "religación" é a pergunta pela raiz e pelo apoio da própria vida pessoal.

d) "Por esto la "religación" es ante todo un "hecho", el hecho mismo en que consiste mi vivir... Es algo que afecta precisa y formalmente al todo de mi realidad humana... Finalmente... es algo básico y radical" (35).

e) "De este "hecho" arranca la vía" (36). "...el "punto de partida y la base de discusión" ses la "religación" como hecho total y como raíz de la construcción de mi Yo" (37).

f) "Esta "religación" es una "experiencia", esto es, una probación física... Algo que nos lleva forzosamente a tener de hacer nuestro Yo. En la "religación" "somos llevados" a hacer nuestro Yo... Somos llevados "físicamente"... de un modo problemático" (38). Y esta experiencia de "religación" puede tornarse, por extensión, experiencia de Dios (39).

g) 'La 'religación' es la experiencia del problematismo de nuestro ser; es un problema físicamente problemático: "es el problema de Dios"” (40).

A presença de Deus nas coisas e no poder do real é o motivo pelo qual devo realizar-me. Desta forma, a via da religación não constitui a prova "de que hay Dios sino de que algo de lo que hay realmente es Dios" (41). É um "hecho" novo, a partir do qual se pode ter um "acesso a la divindad", um "hecho" experienciável, constatável, total e radical (42). Para aceder a este fato será preciso considerar o homem como realidade substantiva pessoal; como ser absoluto relativo que se faz em suas

necessidade de um ser que sustente a contingência e dependência do homem e do mundo, com a qual não é dada; 5) a existência de Deus; 6) conhecimento da relação do homem a Deus; 7) aceitação, por parte do homem, de todos os deveres que tal relação lhe impõe, em cujo cumprimento nasce; 8) a religião (cf. A. GONZÁLEZ ÁLVAREZ, El tema de Dios en la filosofía existencial, Madrid 1945, p. 297-298).

(32) HD 128.

(33) Ibidem.

(34) Ibidem.

(35) Ibidem..

(36) HD 129.

(37) HD 134.

(38) Ibidem.

(39) HD 156, 194, 186.

(40) HD 135 .

(41) HD 230.

(42) HD 128.

(43) SH 151. 
ações fundado na realidade (43); e como pessoa dominada pelo poder do real e religada a ele. A este propósito, afirma o professor López Quintás (44): “A preocupação de Zubiri é situar o problema de Deus com a máxima exatidão, pois, a seu ver, se as questões forem bem colocadas e devidamente articuladas, a ordem interna e a lógica que regem esta articulação se convertem em fonte de luz para compreender as raízes do real”.

Uma vez que a "realidade" que funda o poder que me faz ser está justificada (45), impõe-se agora experimentá-la, provar o que é e como atua. A experiência e a verificação da realidade-fundamento só podem ser realizadas em forma de entrega. Por ora ocupemo-nos do que é esta realidade a que chegamos.

\section{Deus enquanto realidade acedida}

O núcleo básico da "vía de la religación" consiste no fato de a realidade à qual chegamos ser fundamento e não objeto, fundamento de meu ser, cuja atualidade é estar fundamentando-me. De que forma? Sendo a ultimidad do real ou a realidade última. Sendo possibilitante, nas coisas, da configuração de meu Eu. Deus enquanto Deus é somente a possibilidade das possibilidades. E, finalmente, impulsionando-me (impelencia) a realizar-me forçosamente. Deus é o impulso último. Vemos assim que ultimidad, posibilitación e impelencia são dimensões do poder do real, da religación e de Deus mesmo.

\section{(a) A causalidade pessoal}

Pretende-se discutir a relação de causalidade que Deus estabelece com o fundado. Deus é o fundamento último da realidade. Porém, como a fundamenta? É a causa de tudo o que existe? É criador? A teoria clássica (Aristóteles) da causa encerrou toda a possível causalidade sob quatro únicos modos: material, formal, eficiente e final, mas tal teoria só é aplicável aos fenômenos naturais e evapora quando se trata de relações interpessoais (46).

(44) A. LÓPEZ QUINTAS, "La dimensión teologal del hombre según X. Zubiri”: A. BABOLIN (aos cuidados de), Antropologie tipologiche e filosofia della religione. Perugia 1984, p. 245-283, p. 256. Também para A. Savignano, a contribuição de Xavier Zubiri "sublinha com vigor o papel central da "justificação intelectual” (lógica) do problema de Deus" (A. SAVIGNANO, "La dimensione teologale dell'uomo e la teologia fondamentale in Xavier Zubiri": Aquinas 37/1 (1994) 59-87, p. 63).

(45) Falamos em "justificar” a realidade Deus no mesmo sentido que V. M. Borragán Torre a utiliza em seu "La justificación intelectual de Dios en Xavier Zubiri": Naturaleza y Gracia 33 (1986) 253-277, p. 269. Justifica unicamente nosso conseguinte caminhar para a realidade já incoativamente atualizada. Supõe nada mais que um primeiro passo.

(46) "La causa, según Aristóteles, puede considerarse bajo cuatro aspectos: como aquello a partir de lo cual algo se produce, la "materia" (en griego hyle) de que se hace algo y que la cosa continúa siendo: el sustrato (el "de qué"); como la "forma", o el logos, la sustancia o esencia que se manifiesta por la definición, el modelo, la idea o el paradigma (en griego eidos) de la cosa, esto es, el principio organizador y estructurador de la materia que en íntima composición con ella permanece en la cosa (el "qué"); como el "agente" o el iniciador del cambio, el hacedor, el responsable, el origen (el "quién", el "por qué”); como el "fin" (en griego télos), la finalidad, el objetivo hacia el cual se orienta la producción, con miras a lo cual se hace algo, el bien de la cosa (el "para qué"). La tradición ha dado a estos aspectos de las cosas los nombres de causa material, 
Nosso autor sustenta uma idéia de causalidade já exposta em Inteligencia y logos (47) e Inteligencia y razón (48). Causalidade não é produção (metafísica clássica), mas funcionalidade do real enquanto real e não enquanto conteúdos concretos. "Cada cualidad real sentida es sentida en y por sí misma como algo funcional" (49). Deste modo, entre as pessoas existe funcionalidade e autêntica causalidade, à qual Zubiri denomina "causalidad personal", sem que nenhuma das quatro causas consiga explicá-la. Por isso, "hay que reemplazar en este problema la noción de causa por la noción más amplia de funcionalidad de lo real en tanto real" (50), "posibilitando las personas en cuanto personas" (51). Trata-se da unidade entre duas realidades sumamente precisas, duas pessoas. Eu não seria Eu senão em e por Deus. Sou Eu pela presença formal e constitutiva de Deus em mim como realidade pessoal. Por seu lado, segundo esta causalidade, o homem se entrega a Deus aceitando seu ser pessoal de um Deus que é doador de sua realidade e de seu ser. Deste modo, segundo C. Díaz, "Deus está presente mais que pessoalmente, está presente interpessoalmente" (52). E mais, Deus é transcendente interpessoalmente. Quer dizer que Deus está presente no Eu, fazendo-o ser Eu.

A possibilidade de dirigirmo-nos a Deus como um Tu se funda na presença interpessoal de Deus no homem (53). Deus não é interpessoal porque é um Tu, mas, pelo contrário, porque sua tuidad é a expressão humana da presença interpessoal.

(b) Deus presente "en las" e distinto "de las" coisas

Trata-se da questão da articulação entre mundo e Deus. A realidade divina se relaciona com o mundo? Como se relaciona (54)? Como evitar a transcendência como "separação", ao menos estrutural, do mundo e também a imanência como "identificação"? Para Zubiri, Deus não é o que há, mas o que faz que haja. Sua presença nas coisas é formal, de modo que a coisa é sua concreta realidade, "pero, por otro lado, está formalmente constituida en la realidad absolutamente absoluta, en Dios" (55). A coisa, além de ser sua realidade, é uma manifestação de Deus,

causa formal, causa eficiente y causa final. Aristóteles aplica este modelo de explicación causal tanto al mundo natural como al mundo artificial, o del arte" (J. CORTÉS MORATÓ; A. MARTÍNEZ RIU, Diccionario de Filosofía en CDROM: autores, conceptos, textos, Barcelona 1996, verbete: "causa, teoría aristotélica de la").

(47) Inteligencia y Logos, Madrid: Alianza Editorial/SEP, 1982, p. 35-42. Daqui para diante, simplesmente IL.

(48) Inteligencia y Razón, Madrid: Alianza Editorial/SEP, 1983, p. 235-241. Daqui para diante, simplesmente IR.

(49) IR 241.

(50) IR 238.

(51) HD 350

(52) C. DÍAZ, "El hombre y Dios en Xavier Zubiri”: Revista Agustiniana 34 (1993) 165-193, p. 178.

(53) PFHR 71.

(54) Esta é uma das questões mais importantes e profundas abordada pela filosofia de todos os tempos. J. Sáez Cruz ocupa-se dos conceitos de "Deus" e "mundo" e da relação entre ambos em sua tese doutoral Mundanidad y transcendencia en Xavier Zubiri, Salamanca 1990; e em seu artigo "Mundanidad y transcendencia de Dios em Xavier Zubiri": Burgense 33 (1992) 467-525.

(55) HD 149; PFHR 258.

(56) HD 149. 
"consiste simplemente en este doble momento de no ser Dios y de estar, sin embargo, formalmente constituida en Dios" (56). Deste modo, uma separação entre o mundo e Deus é inconcebível (57).

As coisas, que não são sem Deus, porém, não são Deus, possuem realidade pela presença formal de Deus nelas. Deus está presente intrínseca e formalmente na coisa, constituindo-a como real. Porém, não é a coisa, mas um mais "em" ela, um transcendental (58). O "mais" pertence à realidade, nos é presente nela. Como observa Sáez Cruz (59), o "fio condutor é a transcendentalidade da realidade". A presença de Deus nas coisas não é visual, mas em forma de notícia: as coisas são notícias da realidade de Deus (60). Logo, "estar en la plena realidad de una cosa es eo ipso estar en Dios en ella. Ir a Dios es penetrar cada vez más en la cosa misma” (61) e supõe conhecer e experimentar mais de perto o que é a realidade. Portanto, Deus não é transcendente "ao" mundo, como concebia a filosofia escolástica, mas transcendente "no" mundo. Há uma mútua inabitação de Deus "na" coisa e da coisa "em" Deus, de modo que Deus mesmo, como princípio fundante (62), se atualiza formalmente "em e pelo" real enquanto realidade (63). O transcendente pode ser, desta forma, o profundo, o "dentro" (64), o "fundo formal" (65) da própria realidade.

No homem, essa presença de Deus é “própria e peculiar”. Deus é Agente, Ator e Autor das ações do homem por seu caráter fundante. O homem só é real sendo-o em Deus, porém não é Deus senão ele mesmo. É “Dios quien está haciendo con que no sea Dios" (66). Este "não" tem um caráter ativo, pois possibilita que cada homem seja sua concreta realidade e faça ele mesmo seu próprio Eu: Deus não faz meu Eu, mas faz com que eu faça meu Eu. "Si no se mantiene el carácter formalmente activo del "no", se caería en una de las formas de panteísmo, o en una de las formas de extrinsecismo entre Dios y el hombre" (67).

(57) PFHR 69.

(58) Zubiri analisa o que significa "transcendental" em Inteligencia sentiente. A realidade é o transcendental no concreto das coisas reais, porém não como algo acrescentado a suas propriedades, senão sentido nelas. É um "mais" na coisa, mas sem identificar-se com ela.

(59) J. SÁEZ CRUZ, "Mundanidad y transcendência de Dios em Xavier Zubiri": Burgense 33 (1992) 467-525, p. 471.

(60) "Las cosas en cuanto reales nos están "remitiendo" a su propio, intrínseco y formal fundamento trascendente en que están siendo reales" (HD 189). "Y lo que este Dios tiene El de manifestativo es serlo en forma audio-táctil, esto es, a un tiempo como noticia y nuda presencia en tanteo" (HD 190). A. Torres Queiruga declara que Zubiri poderia aqui ter evocado as idéias de Romano Guardini (Los sentidos y el conocimiento religioso e cf. também Religión y revelación) acerca dos "sentidos e o conhecimento religioso". Apesar da diferença de linguagem, há uma profunda coincidência de intenção. Ambos querem ampliar a "inteligência" tanto frente ao racionalismo quanto frente ao fideísmo que teme a razão (cf. A. TORRES QUEIRUGA, "Inteligencia y Fe: el conocimiento de Dios en la filosofía de Zubiri”: Estudios Eclesiásticos 64 (1989) 141-171, p. 147.

(61) HD 175

(62) HD 174-176; Sobre el hombre, Madrid: Alianza Editorial/SEP, 1986, p. 25. Daqui para diante, simplesmente $\mathrm{SH}$.

(63) IR 46

(64) IR 31, 63.

(65) Inteligencia sentiente. Inteligencia y realidad, Madrid: Alianza Editorial/SEP, (1980) 19843 , p. 184-185. Daqui para diante, simplesmente IS.

(66) HD 161.

(67) HD 353.

(68) HD 161; PFHR 258. 
A presença de Deus no homem é "tensão teologal" para seu ser absoluto (68). Deus "está formalmente en mi realidad haciendo con que esta realidad se haga Yo en la realidad divina, sin ser la realidad divina" (69). Daqui se entende a afirmação de Zubiri: "El hombre es Dios finitamente, tensivamente" (70) ou "ser hombre es una manera finita de ser Dios" (71). Essa presença não se dirige à indigência, mas a sua plenitude (72). Deus não é uma realidade da qual nos utilizamos, ou não, conforme seja necessário para suprir nossas deficiências. O Deus da necessidade e da indigência não é Deus, mas uma realidade-objeto que se justapõe à realidade humana. Pelo contrário, Deus é algo constitutivo e constituinte na vida do homem, é o que a possibilita e a leva a sua plenitude, é o apoio último para ser e o motivo que impulsiona (73). Deste modo, deve-se ir contra dois erros. Contra o panteísmo, pois Deus está formalmente nas coisas, mas estas são realmente distintas d'Ele; e contra o agnosticismo, onde Deus seria o grande ausente, o grande estrangeiro do mundo. "La trascendencia de Dios no es ni identidad, ni lejanía, sino trascendencia en las cosas" (74).

(c) As coisas como presença de Deus: a deidade

A religación manifesta Deus como fundamento, mas também as coisas como sede e veículo de Deus. Não são Deus, porém mais que meros "efeitos" d'Ele, visto que sua presença é constituinte. "Dios no está fundamentando las cosas como una especie de espíritu subyacente a ellas; esto sería un absurdo animismo" (75). Deidade e Deus não são o mesmo. Zubiri denomina de deidade ao poder do real, nas coisas, enquanto "último, posibilitante e impelente" (76): "Deidad no es un vaporoso

(69) HD 355.

(70) HD 356.

(71) HD 365.

(72) Para Gianni Vattimo, “enquanto São Tomás e a Idade Média pensavam provar a existência de Deus a partir da ordem do mundo, o pensamento religioso moderno busca as provas de Deus, sobretudo na precariedade e tragédia da condição humana, ao encontrar, naturalmente, muito material à própria reflexão especialmente em tantos clamorosos "fracassos" da razão moderna: Auschwitz, por um lado, e a destruição do colonialismo eurocêntrico, por outro, tornaram insustentável a ideologia do progresso; e hoje, as tantas contradições da ciência-técnica, desde a devastação ecológica até os recentíssimos problemas da bioética, parece que nos devam fazer reconhecer que "agora só um Deus pode nos salvar", como disse Heidegger (na edição em italiano de A. MARINI, Ormai solo un Dio ci può salvare, Parma 1987)” (G. VATTIMO, Creer que se cree, Barcelona 1996, p. 103-104 [título original italiano: Credere di credere, Milano 1996]).

(73) Por ele, o homem "volverá a Dios para poder sostenerse en el ser, para poder seguir en esta vida y en este mundo, para poder seguir siendo lo que inexorablemente jamás podrá dejar de tener que ser: un Yo relativamente absoluto" (HD 160-161).

(74) HD 176.

(75) HD 173.

(76) Noutro texto, Zubiri usa o qualificativo instante ao invés de impelente (EDR 235). I. ELLACURÍA desdobra estas três características fundamentais da deidade ou poder do real numa série de dimensões: 1) um poder "vivo", que intervém de forma ativa na vida do homem, regulando seu curso e configurando-o desde dentro; 2) "fonte" especialmente das coisas viventes; 3) "fundamento solidário" das coisas reais; 4) "fundamento da organização do real", visto que a vida aparece em forma de organismo; 5) "poder do êxito", poder sobre o futuro; 6) "poder próximo, muito nosso", que afeta intimamente; 7) "poder dominante da vida e da morte"; 8) "poder dirigente da coletividade humana", especialmente no momento em que a coletividade se via comprometida; 9) "poder do destino"; 10) "poder reitor da unidade do cosmos", tanto física quanto 
carácter pseudo-divino sino la realidad divina misma de las cosas en cuanto como poder manifiesta su formal constitución en Dios" (77). É uma experiência primariamente pessoal, mas também social e histórica, na qual a idéia de Deus vai adquirindo características sempre mais precisas. "La historia es una magna experiencia histórica de la deidad" (78). "En general puede decirse que la historia de las religiones es la experiencia que los pueblos han hecho de Dios a lo largo de la historia" (79).

\section{A EXPERIÊNCIA DE DEUS}

Recordemos outra vez a questão da religación: o homem é religado, em seu ser, ao poder do real; este é um poder nas coisas reais e, por isso, é uma experiência manifestativa; este poder real é real porque repousa numa realidade-fundamento e constitui a transcendência de Deus nas coisas e, portanto, também na pessoa humana. Logo, resulta que a atualidade de Deus "está incursa de alguna manera en mi propia realidad personal y humana". "Dios está en el fondo de las cosas y, más especialmente, en el fondo de las personas, fundantemente" (80). Portanto, por um lado, pode-se falar em "Deus, experiência do homem", porque Deus doa o poder do real, de uma ou de outra forma, com a realidade fundante; por outro, o homem tem experiência de ser absoluto na medida em que é relativo à realidade fundante, Deus (81).

\section{Conceito de "experiência" em Zubiri}

A "experiência", entendida como aquilo que, direta ou indiretamente, pode se tornar sensível, é um conceito fundamental da filosofia zubiriana (82). Nenhum tipo

moral; 11) "poder do fazer sagrado"; 12) "poder das virtudes morais", quando se busca pôr o supremo modelo dessas virtudes e sua proteção na deidade; 13) "poder que preenche todo" e; 14) "poder que perdura em perfeita perenidade" (cf. I. ELLACURÍA, "La religación, actitud radical del hombre": Asclepio: archivo iberoamericano de historia de la medicina y antropología medica, Madrid XVI (1964) 97-155, p. 135-136)

(77) HD 156.

(78) HD 157

(79) HD 302 .

(80) HD 308, 309.

(81) Em última análise, ao analisarmos a questão da "experiência", nos defrontamos com o problema do conhecimento: do próprio homem e de Deus. Consistindo o homem num estar constitutivamente religado ao poder do real, quando quiser conhecer-se a si mesmo deverá partir das coisas em direção de si mesmo. Quanto ao conhecimento da Divindade, o próprio ser do homem, ao estar religado, é algo afetado por Deus, está sendo n'Ele. Resulta que o conhecimento de mim mesmo, enquanto intelecção de "minha própria e formal realidade profunda" (IR 255) é também um modo de conhecer a Deus enquanto se doa em experiência. Diante disso, González Álvarez deduz, partindo de Zubiri, cinco conseqüências: (1a) Deve-se considerar caduca toda discussão acerca das "faculdades" que primariamente nos levem a Deus. Não se pode ir aonde já se está. (2a) Estamos bem distantes da chamada "filosofia da Ação", visto que se trata do ser mesmo do homem. (3a) Não há uma experiência religiosa sobre a qual recaia uma reflexão posterior que nos leve ao conhecimento de Deus. (4a) Não faz sentido buscar um método para "chegar" a Deus. (5a) O conhecimento "puro" enquanto tal não resulta mais favorável (NHD 434-436; cf. GONZÁLEZ ÁLVAREZ, El tema de Dios en la filosofía existencial, Madrid 1945, p. 231, 233).

(82) Cf. F. ALLUNIS LEARRETA, "El hombre y Dios": Verdad y Vida 44 (1986) 61-80, p. 65-66.

(83) HD 229. 
de fundamento é diretamente apreendido nem pode se tornar apreensível. O alcance da fundamentalidad que a razão lhe outorga por princípio não é sensível, isto é, o caráter racional não reside diretamente no tipo de notas que conformam um conteúdo, mas no alcance de fundamento que se outorga a esse conteúdo. "Y esto lo mismo, tratándose del enigma de la realidad que de un problema de física teórica o de biología o de historia. Lo único que variará es el tipo de fundamentación en función de la índole de lo que nos fuerza a ello" (83).

Para Zubiri, experiência é uma prova à qual se submete algo; uma prova que não é uma mera comprovação, mas "el ejercicio mismo operativo del acto de probar. Es probación física de la realidad de algo" (84). Quer dizer, o fundamento outorga à realidade, tal como esta resultou dada, uma nova dimensão de "fondo", graças à qual os conteúdos dados mostram uma suficiência e uma riqueza intrínsecas. "Probar" (conservando em parte o sentido de "saborear") essa realidade é a experiência; uma prova indireta, já que o que se prova diretamente são os efeitos que o fundamento mostra na realidade tal como está dada.

\section{2. “A parte Dei”, “quoad nos"}

Segundo Zubiri, Deus é quoad nos "realidad absolutamente absoluta, y en tanto que absolutamente absoluta es como está fundamentando las cosas" (85). Deus está nas coisas como a realidad-fundante, que "da-de-si a la realidad": Deus é aquele "por cuya presencia está constituida la realidad, porque esa presencia constituye la realidad de lo real en tanto que real" (86). Deus, como fundamento último, não é algo indiferente, estranho. Seria "un triste concepto de Dios" (87). Zubiri opõe-se a qualquer concepção de Deus como algo alheio ao mundo. Deus não é algo "totalmente outro" porque desse modo resultaria inacessível e terminaria num Deus otiosus (88). Deus se manifesta no mundo fundamentando a realidade última das coisas e, ainda que racionalmente, é preciso estabelecer seu caráter transcendente. Trata-se de uma transcendência "en la realidad y en las cosas", nunca de sua total estranheza.

Zubiri prossegue fazendo um pequeno excurso sobre a criação como a "configuración de Dios ad extra" (89). A criação como "la vida misma de Dios proyectada libremente ad extra, por tanto en forma finita" (90). $\mathrm{O}$ ad extra equivale, pois, a "ser

(84) HD 95.

(85) HD 311.

(86) HD 313

(87) HD 344.

(88) "Un dios ocioso es un dios real pero que no interviene en la vida de la persona; la vida del hombre no está entonces trazada en función de Dios. Es la realidad-fundamento de Dios, reducida a realidad-objeto... En el fondo, el theós de Aristóteles es un dios super-ocioso: no solo no se ocupa del hombre, ni el hombre de él, sino que no puede tener relación ninguna con el cosmos" (HD 260).

(89) HD 379. Neste caso, segundo Sáez Cruz, Zubiri apóia-se numa metafísica de corte neoplatônico, inspirada na "ontologia integral do ser finito" (NHD 528) dos Padres Gregos (cf. J. SÁEZ CRUZ, "Mundanidad y transcendência de Dios em Xavier Zubiri": Burgense 33 (1992) 467-525, p. 520).

(90) HD 313.

(91) HD 381 . 
como Dios" (91). Não se trata de nenhum "emanantismo" (92); requer um ato de vontade positiva, um "fiat criador" (93). Zubiri distingue dois tipos de realidades criadas: o das realidades que designa "esencias cerradas" (94) -as coisas que são de suyo- e o das realidades que designa "esencias abiertas" (95) - o homem, que não somente é de suyo, mas também suyo. Conclui dizendo que o modo de "dar-de-si" da realidade fontanal (96) às essências abertas é "donación” pessoal. Quer dizer que Deus doa ao homem a verdade real. Verdade real é a atualidade do real na inteligência enquanto real: "con esa verdad real y en esa verdad real, el hombre, con la donación de Dios, está haciendo su propia persona relativamente absoluta" (97). E por esta razão conclui-se que "forzosamente la donación de Dios como verdad real es justamente donación experiencial (...). Decir, entonces, que Dios es experiencia del hombre, consiste pura y simplemente en decir que está dándose al hombre en un darse que es experiencia", já que o homem é um animal de realidades, é um animal de experiências (98).

Deus se doa de três formas distintas: com a absoluta experiência em forma universal; num segundo momento mais próprio, a doação é uma realidade absoluta -a graça incriada e a graça criada (99)-; e, finalmente, um modo mais íntimo e absoluto de doação que é a verdade real de Deus em pessoa - é o caso da Encarnação segundo a fé cristã, "que, pero, como posibilidad puede ser pensada por la razón humana" (100).

\section{3. "A parte hominis"}

Em sua realidade, o homem está experienciando Deus. Não quer dizer que tenha experiência de Deus, mas que "é" experiência de Deus. Não que Deus seja experiência como a de um objeto, ou um estado em que o homem se encontra, mas que o homem está fundamentado e que Deus é a realidade fundamentante e, por isso, a experiência de Deus por parte do homem consiste na experiência de estar funda-

(92) NHD 494.

(93) Sobre la esencia, Madrid: SEP, (1962), Alianza Editorial, 19855, p. 49. Daqui para diante, simplesmente SE; SH 591.

(94) SR 192, 193, 196, 199, 200, 201, 202, 215, 237; Estructura dinámica de la realidad, Madrid: Alianza Editorial/Fundación Xavier Zubiri, (1989) 19952, p. 100-104, 207s, 323. Daqui para diante, simplesmente EDR. El problema teologal del hombre: Cristianismo. (Edição de Antonio González). Madrid: Alianza Editorial/Fundación Xavier Zubiri, 1997, p. 201. Daqui para diante, simplesmente PTHC.

(95) SR 193-202, 209, 214-218, 224, 227-230, 232, 233, 237, 238; EDR 100-104, 204, 206ss, 219 225, 312, 323; PTHC 201.

(96) Enquanto realidade "fontanal", Deus é realidade fundamental e "fundamentante", não no sentido de uma natura naturans, senão no sentido de que é algo por cuja presença a realidade está constituída. Por exemplo: não é que Deus queime no fogo senão que faz com que o fogo queime; faz com que o fogo queime fazendo que o fogo seja fogo.

(97) HD 316. Não é a verdade lógica ou a verdade de uma afirmação, de um juízo; tampouco a verdade ontológica tradicional, senão algo muito mais elementar.

(98) HD 316, 317

(99) HD 319. Para aprofundar, veja-se T. LEÓN MARTÍN, La gracia en X. Zubiri: de la autodonación de Dios a la deificación del ser humano, Roma 1998.

(100) HD 319.

(101) HD 327. 
mentado fundamentalmente na realidade de Deus: "Yo (...), respecto de Dios, soy una realidad relativamente absoluta (...), porque este carácter absoluto lo tengo cobrado frente a la realidad haciéndome persona (...). Por consiguiente, la experiencia de hacerme persona es la experiencia de lo absoluto" (101). É neste sentido que Zubiri escreveu: "El hombre es una manera finita de ser Dios" (102).

A concreção da vida humana como experiência de Deus é a resposta por parte do homem a essa doação fundamentante. E o homem responde com a "fé", isto é, "la entrega de mi persona a otra persona, en nuestro caso a la persona de Dios" (103). Se a realidade nos possui integralmente, a fundamentalidad real implica uma atitude integral da pessoa. "Es entrega a una persona en tanto que esta persona envuelve verdad" (104). Não se trata de uma verdade comunicada pela pessoa à qual se entrega (105), mas da verdade que é ela mesma enquanto realidade.

A fé é um modo de causalidade interpessoal entre a pessoa divina e a pessoa humana (106). Deus, enquanto verdadeiro, está intrínseca e formalmente presente na pessoa, "por esto, entregarse a Dios en la fe es entregarse al propio fondo transcendente de mi persona" (107). E, vice-versa, "la fe en la transcendencia personal es ya fe en Dios" (108). Entregar-se não é abandonar-se -o que seria fugir de si-, ou esperar que Deus faça as coisas por si mesmo, sem intervenção minha -o que seria comodidade ou desespero-. A entrega é atitude e ação positiva, ativa. Neste sentido, toda a entrega assume um caráter concreto: "es acatamiento, súplica y un refugiarse" (109). Acatar não significa, primariamente, obedecer; é algo derivado. É, antes, essa espécie de reconhecimento do relativo que sou frente à pessoa absolutamente absoluta que é Deus. É como que um desaparecer ante Deus. A entrega é também súplica, que é a essência da oração. O homem suplica a Deus como "fortaleza" de sua vida, como seu "refúgio".

Em síntese, acatamento, súplica e refúgio "son momentos de la fe, porque es la fe lo que los hace posibles y necesarios" (110). Pela fé, o homem se entrega à realidade pessoal de Deus enquanto manifesta -é acatamento-, enquanto fiel -é a súplica- e enquanto seu indefectível ser real -é um refugiar-se. Tal é a essência da entrega do homem a Deus, do acesso total do homem a Deus. Dessa forma, o Deus a que se chega não é o Deus dos filósofos, mas um Deus idêntico ao Deus das religiões, a quem cabe adorar e rezar.

Esta tripla especificação leva a qualificar o ato da fé como: asentimiento personal, certeza firme e opción libre. Como asentimiento personal há uma incorpo-

(102) HD 154, 327.

(103) HD 212; PFHR 81, 83. Zubiri rechaça a definição tradicional de fé concebida como "el asentimiento a un juicio fundado en el testimonio de otro" como insuficiente. Quer romper, desde o início, os "limites do assentimento intelectual" reduzido a um "juízo", para compreender a fé como "entrega" (HD 211-212).

(104) HD 212, 221.

(105) HD 213.

(106) HD 215-216.

(107) HD 216.

(108) Ibidem.

(109) HD 216-217.

(110) HD 216.

(111) HD 218. 
ração interpessoal em enriquecimento mútuo: "el que se adhiere ha potenciado su propia verdad real en y con la verdad real de la persona a quien se adhiere; se ha hecho, por así decirlo, más verdadero; más manifiesto, más fiel, más efectivo" (111). Como certeza firme, que por seu caráter pessoal implica energia positiva, permite captar a fé também como estado: algo no qual se está porque se recebeu. É a fé em sua dimensão social e comunitária, dimensão que constitui o "mundo de la fe" no qual se nasce e que supõe também riqueza de possibilidades (112). Como opción libre implica toda a realidade da pessoa "en orden a la figura radical y última de nuestro ser relativamente absoluto, de nuestro Yo" (113).

Em seguida, Zubiri indica a "relación" que há entre a inteligência e a fé (114). Sua intenção primeira é afirmar a unidade conhecimento-fé (115), distanciando-se do clássico credo ut intelligam/intelligo ut credam (116). Se, de um lado, a fé não pode reduzir-se a uma mera adesão intelectual, de outro, é necessário sublinhar o imprescindível momento intelectivo de qualquer tomada de atitude e de qualquer fé possível, mesmo que não se trate de fé teologal (117). Com certeza, a mera adesão intelectual não leva automaticamente à atitude de entrega, mas, por outro lado, esta necessita imprescindivelmente do momento intelectivo porque se trata de "realidade" e realidade significa sempre o momento intelectivo de toda a possível experiência humana (118). Esta é uma estrutura geral de todo o pensamento de Zubiri, que o próprio filósofo denomina "inteleccionismo", distanciando-se do tradicional "inte-

(112) HD 218-220.

(113) HD 220-221.

(114) Sobre tal aspecto da filosofia de Zubiri, pode-se ver o interessante artigo de A. TORRES QUEIRUGA, "Inteligencia y Fe: el conocimiento de Dios en la filosofía de Zubiri": Estudios Eclesiásticos 64 (1989) 141-171.

(115) "La fe como camino "para" el conocimiento y el conocimiento como camino "para" la fe" (HD 238). Definitivamente, "la unidad radical de conocimiento de Dios y de fe en El consiste en voluntad de verdad" (grifo do próprio Zubiri) (HD 244).

(116) "Creio para entender", frase de Santo Anselmo de Canterbury (1033-1109), que resume a postura clássica da primeira Escolástica diante do problema da relação entre razão e fé, tal como aparece sobretudo nos textos de Santo Agostinho e Anselmo. Esta formulação, que dá uma primazia clara à fé, se atenua com outras formulações mais débeis, em que o conhecimento aparece como uma preparação à fé ou uma exigência da mesma: "a fé que busca entender". Esta última frase de Santo Anselmo (Fides quaerens intellectum) expressa bastante adequadamente a atitude geral de toda a Escolástica: compreender e justificar a fé" (J. CORTÉS MORATÓ; A. MARTÍNEZ RIU, Diccionario de Filosofía en CDROM: autores, conceptos, textos, Barcelona 1996, verbete: "credo ut intelligam"). Para um aprofundamento da questão histórica, remetemos a G. SÖHNGEN, "Credo ut intelligam": Lexikon für Theologie un Kirche 3 (1959), p. 89-91.

(117) "lo teologal no es lo teológico por dos razones: a) porque lo teologal es tan solo fundamento del saber teológico, pero no es el saber teológico mismo; b) porque lo teologal es ciertamente una dimensión humana, pero es justo aquella dimensión según la cual el hombre se encuentra fundado en el poder de lo real" (HD 382). "Teologal... significa que es una dimensión humana que envuelve formal y constitutivamente el problema de la realidad divina... Lo teológico envuelve a Dios mismo" (HD 12). "Teologal" tem um "sentido de uma propriedade de Deus ou do divino enquanto tal, diverso do "teológico", que aponta melhor a uma propriedade da ciência teológica ou do divino enquanto término dela" (PTHC 584, nota 1). Nesse sentido, "fé teologal" é a entrega da realidade humana ao poder do real. É a entrega à religación à "ultimidade" que me faz ser.

(118) A este propósito, González Álvarez afirma: "Não entendo a fé senão incidindo na razão..., e não concebo uma inteligência humana sadia que não se abra à fé” (A. GONZÁLEZ ÁLVAREZ, El tema de Dios en la filosofía existencial, Madrid 1945, p. 302).

(119) IRE 284; SH 457. "Tendência a expressar o que as coisas são somente através de conceitos 
lectualismo" (119). Devemos, portanto, opor-nos a qualquer tipo de fideísmo ou de irracionalismo e descartar toda a "fé cega", pois o acesso ao fundamento é sempre produto de uma busca racional.

\section{a) Modos de experiência de Deus}

Um dos modos mais radicais de toda a pessoa fazer experiência de Deus é a vontade de verdade real (120), na qual, frente à mera "voluntad de verdad de las ideas", opta-se por uma entrega sem reservas a essa realidade que nos está fundando. A vontade de verdade real é plasmada num processo intelectivo no qual se oferecem ao homem diversas possibilidades de ser homem. Neste ponto, entra a liberdade como maneira radical de ser realidade absoluta: "ser libre es la manera finita, concreta de ser Dios, ser libre animalmente" (121). A liberdade é "la experiencia absoluta del absoluto de Dios" (122).

A vontade de verdade real é distinta segundo a índole da realidade a que se dirige. Pode ser: a da realidad-objeto, que revestirá duas modalidades, conforme a consideremos por si mesma (vontade "científica") ou queiramos fazer algo com ela (vontade "de elaboración") (123); e a da realidad-fundamento, a qual, por sua própria natureza, sendo em e por si mesma, é sempre "para mí", porque meu ser se realiza constitutivamente nela. "De donde resulta que en el "para-mí" de la realidadfundamento tenemos a una la verdad real de la realidad y la verdad real de mi persona, mi verdad real" (124).

E Zubiri sugere outras maneiras: "la experiencia de la gracia de Dios, o de Dios como gracia" (125), e a vida humana de Cristo, o modo mais absoluto e íntimo de deiformidad, a propósito da qual afirmou: "No era un hombre, además de ser Hijo de Dios, sino que era la manera concreta como él vivía humanamente su propia filiación divina" (126). A experiência de Deus toca todas as dimensões da pessoa humana. Portanto, é uma realidade individual e pessoal e, ao mesmo tempo, social e histórica, da qual a história das religiões é o documento concreto. Pode-se dizer que Deus é experiência do homem na sociedade e na história.

A história, por sua vez, é própria e rigorosamente, dentro dos limites de sua historicidade, uma experiência de realidade (127) e, desta forma, uma experiência

abstratos, deixando de lado toda consideração concreta e vital das coisas mesmas. Devido a esta primazia exagerada outorgada ao entendimento, normalmente considerada um excesso, o termo é empregado em sentido pejorativo" (tradução nossa) (J. CORTÉS MORATÓ; A. MARTÍNEZ RIU, Diccionario de Filosofía en CDROM: autores, conceptos, textos, Barcelona 1996, verbete: "intelectualismo").

(120) HD 245-258.

(121) HD 330.

(122) HD 334.

(123) HD 250-251.

(124) HD 252.

(125) HD 330. Por parte de Deus, abarca todos os seus dons e, por parte do homem, é a experiência de pôr-se nas mãos de Deus, isto é, a entrega do homem a seu fundamento. Todos os homens têm esta experiência, mesmo que não o saibam (HD 330-331).

(126) HD 331.

(127) HD 338.n

(128) HD 321. 
de Deus. Zubiri chega a dizer: "La historia es esencialmente experiencial, es Dios dándose como experiencia histórica" (128) e cita, para tal, o caso do pobre de Israel. Nos diferentes momentos históricos de Israel, aquele povo experimenta Deus como "Aquele que é", o "Deus da Aliança", o "rei", o "chefe" de um Estado, etc (129). A história está essencialmente aberta pela própria estrutura intelectiva da razão, o que não significa que ceda a qualquer tipo de relativismo, mas a algo essencialmente distinto que o fílósofo chama "aspectualismo" (130).

\section{b) Atitudes na experiência de Deus}

Além do teísmo, existem três atitudes na experiência de Deus: o agnosticismo, o indiferentismo e o ateísmo. O agnosticismo não consiste numa carência de saber, mas num "proceso intelectivo" real. O agnóstico intelige a realidade como algo que "imperiosamente busca, pero no encuentra" (131). Como todo o homem, "tateia". O agnosticismo "es un tatear sin encuentro preciso", no qual brilha, de modo peculiar, a "voluntad de fundamentalidad" (132).

Há um outro grande número de pessoas que vive em indiferença fundante. Zubiri a estuda como "una actitud absolutamente precisa" (133), apoiando-se no fato radical do não descobrimento da diferença entre Deus como realidade-fundamento e Deus como realidade-objeto. Isto leva a uma intelecção "indiferente", na qual tanto importa um Deus ocioso, um Deus fundante, ou um Deus visto com indiferença (134). Há intelecção real do fundamento, porém é indiferenciada: "que Dios sea lo que sea". À indiferença intelectiva, responde, no campo da vontade, a "despreocupação". Despreocupação é um estado positivo; não é não-opção, mas estrita opção, a opção por não se ocupar daquilo que "está ahí" indiferentemente (135). O despreocupado vive "dejándose vivir" porque, por detrás de sua indiferença fundamental, o que faz é "afirmar energicamente que vive e quiere vivir". E fá-lo com uma "voluntad de vivir penúltima": é a "penultimidad de la vida" (136). O desinteressado de Deus vive na superfície de si mesmo: é vida constitutivamente penúltima.

Por último, Zubiri trata do ateísmo. Sendo a religación um fato, comporta a impossibilidade lógica da hipótese atéia (137). É preciso então esclarecer a possibilidade do ateísmo (138). O ateísmo se refere às pessoas para quem Deus "jamás fue

(129) HD 336-341.

(130) HD 304.

(131) HD 237, 272-273.

(132) HD 274-275.

(133) HD 279.

(134) "Esta indiferencia tiene muchos matices, desde el admitir la realidad de Dios inteligida indiferentemente, hasta, en el extremo opuesto, una cierta indiferencia respecto de la realidad misma de Dios, pasando por la idea de la ociosidad divina" (HD 277).

(135) HD 278.

(136) HD 279-280.

(137) Cf. M. MICHELETTI, "La "struttura" del problema di Dio. Criteri di intelligibilità e problema della verità nella filosofía della religione di Zubiri": Xavier Zubiri, Perugia 1980, p. 97-116.

(138) "Si el hombre es constitutivamente religado, el problema estará, no en "descubrir" a Dios, sino en la posibilidad de "encubrirlo" (NHD 448).

(139) Podem existir dois estilos fundamentais de ateísmo, afirma Ellacuría: "um ateísmo ao qual se 
problema" (139). A vida não coloca, para estas pessoas, problema algum: é o que é e nada mais. É "vida atea" que repousa sobre si mesma, sem necessidade de ir "contra" nada nem ninguém (140), vida tomada "en" e "por" si mesma "y nada más" (141), "a-tea" no sentido meramente privativo do prefixo "a". No fundo, talvez não seja um verdadeiro ateísmo, como atesta Zubiri: "Es más bien la divinización o el endiosamento de la vida. En realidad, más que negar a Dios, el soberbio afirma que él es Dios, que se basta totalmente a sí mismo. Pero, entonces, no se trata propiamente de negar a Dios, sino de ponerse de acuerdo sobre quién es Dios" (142). O ateu leva a cabo uma opção, a da "auto-suficiência da vida", tomada como o que é e nada mais (143). É interpretação do homem como facticidade auto-suficiente (144). $\mathrm{O}$ ateísmo radica-se na compreensão do poder do real como um fato e nada mais que um fato, a "pura facticidad" do poder do real (145).

No entanto, a realidade segue sendo problemática também para esta pessoa. O que sucede é que o ateu, talvez sem se dar conta, soluciona este problema pela via da facticidade. "El ateísmo es justamente la fe del ateo"146. Contudo, optar pela facticidade do poder do real é uma "interpretação", como o é a admissão da realidade de Deus. Deste modo, "el que va a Dios, admite la existencia de Dios razonadamente. Y el que no va tiene que probar que no va. Tiene que dar razones" (147).

Zubiri conclui:

"Si el hombre descubre la realidad fundamental en su proceso intelectivo y volitivo, de voluntad de verdad, y el ateo no, es que el ateo, a diferencia del

chega pela negação do homem, pela aniquilação de sua riqueza mais radical, e um ateísmo ao qual se chega pela afirmação do homem, seja por exaltação, ou seja, por resignação" (I. ELLACURÍA, "La religación, actitud radical del hombre": Asclepio: archivo iberoamericano de historia de la medicina y antropología medica, Madrid XVI (1964) 97-155, p. 146). Zubiri se situa na segunda perspectiva, já que possui uma visão positiva do homem e destaca nossa situação como de exaltação do homem.

(140) HD 281.

(141) "La persona se implanta en sí misma y la vida adquiere un carácter absoluto. Es lo que San Juan llamó, en frase espléndida, "la soberbia de la vida". (...) En ella, el éxito de la vida oculta su propio fundamento, y el hombre se desliga de todo implantándose en sí mismo" (NHD 449). A citação de São João refere-se a 2, 16.

(142) NHD 449-450. No artigo "En torno al problema de Dios", Zubiri defende "a soberba, o êxito da vida", como causa do ateísmo. A soberba revestiu três formas -o homem "é" pessoa e "tem" vida e história- donde derivam três espécies de pecados -peccatum personale, peccatum originale e pecado histórico-, que dão origem a outras tantas classes de ateísmo (NHD 451-452). E não falta nem mesmo o antídoto contra o ateísmo: "el fracaso de la existencia que se religa a su puro factum" e que "asegura siempre la posibilidad de un redescubrimiento de Dios" (NHD 450-451).

(143) HD 284. "El ateo, de una u otra forma, hace de sí un Dios" (NHD 155).

(144) C. Díaz conclui que: "si la fe es entrega formal a una persona en cuanto verdadera, el ateo se entrega formalmente a su propia realidad formal como única y suficiente realidad personal verdadera, y en esta entrega consiste la fe del ateo. El ateo se entiende entregado a sí mismo y se acepta como tal; por tanto lleva a cabo una opción, de modo que el ateísmo no es menos opcional que el teísmo" (C. DÍAZ, "El hombre y Dios en Xavier Zubiri": Revista Agustiniana 34 (1993) 165-193, p. 184).

(145) HD 282-284.

(146) HD 284, 282-285. Definitivamente, para Zubiri, o ateísmo é “impossível sem um Deus. O ateísmo é possível somente no âmbito da deidade na religación” (NHD 393).

(147) HD 342.

(148) HD 343. 
teísta que ha descubierto a Dios, se encuentra con su pura facticidad encubriendo a Dios: es el encubrimiento de Dios frente a su descubrimiento. No es carencia de experiencia de Dios. Es una experiencia en cierto modo encubierta" (148).

O Cristianismo responde ao ateísmo, quando verdadeiro, através da "manifestação da face genuína de Deus e da religião" e da "adequada exposição doutrinária, mas também de pureza de vida da Igreja e de seus membros" (149). Na Constituição Pastoral Gaudium et Spes, a Igreja ressalta como a "morte de Deus" leva à morte do homem e do humanismo. Em segundo lugar, a fé contesta a impossibilidade do ateísmo dar uma solução satisfatória aos "enigmas da vida e da morte, da culpa e da dor". Enfim, contesta que o problema de Deus, cuja solução deveria dar sentido à vida do homem, possa não se apresentar, pelo menos "em certos momentos da sua vida e particularmente nos acontecimentos de maior relevo" (150).

\section{A unidade entre Deus " $e$ " o homem}

Para explicar a "índole genérica da unidade de Deus "e" o homem", Zubiri põe de novo em jogo a causalidade pessoal, que induz a um tipo de "unidade-na-distinção". Usa a categoria da "implicación" e diz expressamente: "Es una manera de estar implicado en Dios y de Dios estar complicado conmigo" (151). "Entre Dios y el hombre hay una distinción real, pero que no solamente no es separación sino que es una implicación formal" (152). Volta a dizer que a pessoa humana não seria pessoa humana se não estivesse de algum modo e formalmente implicada (153), porque o homem é absoluto relativamente, em referência a Deus. Uma coisa é Deus não necessitar dos homens para ser pessoal, e uma outra é que a recíproca seja correta: "Yo no soy Yo más que por la presencia formal y constitutiva de Dios en mí como realidad personal" (154).

Zubiri reforça esta implicação entre o homem e Deus com a categoria de "tensión teologal" (155). Em sua religación, o homem está formalmente apoiado em Deus. Este apoio é uma tensão entre o homem e Deus, na qual consiste a essência teologal da religación (156). Assim, o homem é experiência de Deus ou "tensión teologal" entre dois absolutos, um fundante e outro fundado. "Esta presencia formal constituyente de Dios en la vida del hombre" (157) como apoio é causalidade for-

(149) Concílio Vaticano II, Gaudium et Spes 19, 21.

(150) Concílio Vaticano II, Gaudium et Spes 21.

(151) HD 354

(152) Ibidem.

(153) Esta explicação recorda o pensamento de Nicolau de Cusa em dizer que as coisas, o mundo, está complicado em Deus e que o mundo é a explicação de Deus.

(154) HD 352.

(155) “A unidade entre Deus e o homem é, por conseguinte, tensão teologal” (HD 354; também HD 161; PFHR 250).

(156) HD 363.

(157) HD 161. O homólogo do que é a tensão teologal no homem, nas coisas, Zubiri chama de "fontanalidade" (fontanalidad). "Fontanalidade" é "a presença de Deus nas coisas como constituinte dar-de-si... "fazendo que sejam reais"” (HD 177).

(158) HD 354. 
malmente pessoal, é "unidad interpersonal tensiva" (158). "La tensidad es formalmente la experiencia del hombre como experiencia de Dios. Y la experiencia de Dios es última y radicalmente experiencia de esta tensidad" (159), "cuya expresión humana y vivida es la inquietud" (160) da constituição de seu Eu. Nesta tensão Deus tem uma função estritamente pré-tensora, sua ação doadora é preponderante e iniciante. Deus tem a primazia absoluta (161). Zubiri conclui dizendo: "Dios, realidad absoluta, está formalmente en mi realidad haciendo que esta realidad se haga Yo en la realidad divina, sin ser la realidad divina. Y en esta unidad es en lo que consiste el carácter experiencial de la 'y”' (162).

Finalmente, Zubiri procura explicar em que consiste esta unidade experiencial pela qual Deus se doa a mim em experiência com a realidade absoluta, constituindome na minha realidade relativamente absoluta. Explica ainda como o homem é experiência de Deus e experiência do absoluto em Deus; como a constituição formal do Eu é uma doação; e como a unidade da tensão teologal é a unidade entre doação e experienciação.

O homem pode ser Deus tensivamente de muitas maneiras: na maneira como o homem, que radicalmente é "personeidad", se afirma e se realiza como pessoa; na graça, no sentido de São Paulo ou do hesed no Antigo Testamento; e de maneira muito superior, no caso de Cristo, que é "aquel modo en el que el Yo es una reactualización de la suidad, pero de una suidad que no le pertenece, es decir, la realidad substantiva que pertenece a otro" (163). Zubiri conclui El Hombre y Dios sintetizando todo o propósito e a marcha do livro como tal sob a religación:

"religación al poder de lo real, entrega intelectiva a Dios en la voluntad de verdad, experiencia tensiva de Dios: he aquí los tres conceptos que expresan tres momentos de un solo fenómeno, de una sola estructura, cuya unidad intrínseca y formal constituye la dimensión teologal del hombre [...] como constitución del acto en el cual se afirma como relativamente absoluto en el seno de la realidad en tanto que Yo" (164).

\section{ALGUMAS CONCLUSÕES}

Malgrado as supressões e acréscimos dos editores, El hombre y Dios pode ser considerada uma autêntica obra de Zubiri. Quem conhece as obras zubirianas pode perceber uma grande coerência entre elas, especialmente se considerar as grandes linhas de seu pensamento: realidade e inteligência, mundo e cosmos, indivíduo,

(159) HD 355.

(160) HD 363. Zubiri não se refere à inquietude por ser feliz, mas a algo muito mais radical: "o que vai ser de mim?" e "o que faço eu de mim mesmo?".

(161) HD 354, 362.

(162) HD 355 .

(163) HD 358. Aqui Zubiri efetua uma interessante explicação da união hipostática em Cristo (HD 358-361).

(164) HD 365.

(165) Cf. A. PINTOR-RAMOS, "Religación y 'prueba' de Dios en Zubiri”: Razón y Fe, Tomo 218 , n. 
sociedade e história, as conceituações do ser, da verdade, entre outras. A obra é realmente original no campo estritamente metafísico -ou da chamada "teologia natural"- por sua peculiar abordagem do problema de Deus. Segundo Pintor-Ramos (165), a questão em Zubiri não consiste tanto em saber se nosso pensamento encontra algo que possa designar por Deus, mas em que via concreta se coloca seu acesso e qual é o problema a que responde.

C. Díaz (166) levanta a suspeita de que Zubiri queria, mas não conseguiu, livrar-se de uma característica própria: a tradição filosófica. Um exemplo: para designar Deus utiliza a expressão realidade-fundamento, e dela diz (tautologia que se repete muitas vezes) que fundamenta, que funda e que é o fundo último. Pois bem, estas são algumas características célebres da natura naturans que ele mesmo rechaça como sendo imanentista (167).

As provas clássicas da existência de Deus se moviam em esquemas puramente objetivistas: a) a entificação da realidade divina levava a um Deus-objeto; b) a logificação do conhecimento de Deus faz deste a objetivação de uma prova lógica. Diante desta lógica, os tempos modernos sentiram pura indiferença. Por isso, Zubiri sentiu a necessidade de uma nova fundamentação para o tema de Deus. Para ele, o problema de Deus já está dado na realidade pessoal do homem. O homem descobre Deus a partir desta realidade e como meio de realização em seu viver. Desenvolve uma nova "vía de la religación", da qual vislumbramos as verdadeiras consequiências -o acesso do homem a Deus, o homem como experiência de Deus, Deus como experiência do homem, etc- que implicam uma nova concepção de Deus como realitas fundamentalis (168): a) Deus como realidade pessoal frente à coisificação teísta; b) o problema de Deus como realidade vital frente à objetivação ou conceptualização logicista. Para Zubiri, a estrutura funcional de Deus na vida é: "fundamento (y no objeto), lo es de su plenitud (y no de su indigencia), y lo es en forma de tensión dinámica (y no de yuxtaposición)" (169). Implica ainda numa nova visão do conceito de agnosticismo, de ateísmo e de indiferentismo, ou do que denominou "la dimensión teologal del hombre".

Avaliando o "esboço" zubiriano pela sua razoabilidade torna-se muito vantajoso. Oferece uma rica compreensão de Deus enquanto presente nas coisas. Se aceitarmos a religación da pessoa ao poder do real como um hecho, os demais passos.

1081 (nov. 1988) 319-336, p. 334.

(166) Cf. C. DÍAZ, "El hombre y Dios en Xavier Zubiri": Revista Agustiniana 34 (1993) 165-193, p. 188-189. Díaz dirige sua crítica também à magna quaestio do poder do real. Na obra de Zubiri, o poder do real dá a impressão de ser uma enorme atração. Tal sensação é agravada, segundo o autor, pela afirmação de que "o homem não vai a Deus pela indigência, mas pela própria plenitude da vida". E indaga: "como seria possível fazer-se pessoa à margem da experiência histórica da indigência?". Por fim, critica o que se refere aos atributos divinos: "nenhum deles está suficientemente justificado; nenhum deles traz novidade ao extenso catálogo histórico de divinis nominibus; e nenhum deles escapa ao que poderíamos denominar 'traço antropomorfizante"”. Contudo, conclui seu artigo manifestando que o que interessa em Zubiri não são somente seus acertos, senão as aporias férteis das quais se torna possível um avanço no pensar". Considera "Zubiri o personalista espanhol mais importante" (Ibidem, p. 191-193).

(167) SH 466, 468; EDR 91.

(168) HD 326, 327.

(169) HD 163. 


\title{
RESUMEN
}

El presente artículo pretende analizar como Xavier Zubiri (1898-1983) aborda el problema de Dios y de su acceso y la experiencia de Dios a partir de su obra El Hombre y Dios (1983). El filósofo español muestra que el problematismo de la persona humana es el problema de Dios y, a partir de la insuficiencia de las vías tradicionales de acceso a Dios, traza el esbozo de la "vía de la religación", de la cual vislumbramos las verdaderas consecuencias -el acceso del hombre a Dios, el hombre como experiencia de Dios- implicando en una nueva concepción de Dios como realitas fundamentalis. Dios no es más una realidad-objeto, sino una realidad absolutamente absoluta, fundamento del Ser como ultimidad, posibilitación y impelencia. El hombre, a su vez, hace experiencia de Dios en tanto que se siente fundamentado y manifiesta la "voluntad de verdad real". Por tanto, la unidad experiencial entre Dios y el hombre es tensión dinámica, es la "dimensión teologal del hombre".

Palabras-clave: Xavier Zubiri, problema de Dios, problema del hombre, experiencia de Dios, dimensión teologal del hombre.

O problema de Deus e do seu acesso e a experiência de Deus

Everaldo Cescon

\begin{abstract}
:
This article intends to analyse Xavier Zubiri's (1898-1983) approach to the problem of God, the access to Him and the experience of God in his work El Hombre y Dios (1983). The Spanish philosopher claims that the problematism of the human person is the problem of God. Given the insufficiency of the traditional ways of access to God, he provides an outline of the "way of relegation", from which we see the true consequences -man's access to God, and experience of God - entailing a new conception of God as realitas fundamentalis. God is not a reality-object anymore, but the absolutely absolute reality, foundation of the ultimate, possibly and compulsive Being. Man develops an experience of God in which he feels founded and shows the "will of real truth". Therefore, the experiential unity between God and man is a dynamic tension; it is the "theological dimension of man"
\end{abstract}

